\title{
Development of a software package for the tractor fleet formation in agricultural organizations
}

\author{
Valeria Zubina ${ }^{1, *}$ and Alexey Kutyrev ${ }^{1}$ \\ ${ }^{1}$ Federal Scientific Agroengineering Center VIM, 1-st Institutsky proezd, 5, Moscow, 109428, Russia.
}

\begin{abstract}
A set of computer programs for the formation of the tractor fleet, taking into account its quantitative and age composition, technical level, loss and shortage of products associated with the deviation of the agrotechnical period in the non-Chernozem zone of Russia and the annual cost of repair and maintenance of tractors. The program is universal for any structure of Park of farms and any region. The menu of program modules is presented. The program will rationally complete the machine and tractor fleet of agricultural enterprises, as well as more reasonably choose the direction of development of the tractor design and determine the most costeffective, performance and design characteristics of tractor models at the design or procurement stage.
\end{abstract}

\section{Introduction}

Scientists around the world are conducting research on the development of new methods of weed control. The effectiveness of these methods depends on the designs, principles and modes of operation of specialized machines. Modern manufacturers of agricultural machinery and equipment pay great attention to the development of machines for weed control without the use of chemicals, with the aim of transition to environmentally friendly (organic) agriculture. The development of these principles results in trailed devices that use tractor energy, gas or hydraulic equipment to carry out tillage in rows of vineyards, berries and in areas near the trunk of fruit trees [1-2]. The practical application of an environmentally friendly method of removing weeds using high-pressure water jets is hampered by the lack of technical solutions to ensure compliance with the treatment regimes in field conditions [3,4]. The substantiation of the parameters of new environmentally friendly technologies and technical means to combat weed vegetation in the near-forest zone of garden plantations with an automated system of adaptation of the working body is an actual problem and has an important scientific and industrial importance.

\footnotetext{
* Corresponding author : lera_zubina@mail.ru
} 


\section{Materials and methods}

A set of computer programs for forming a tractor fleet was developed in the C Sharp programming environment in the Microsoft Visual Studio program. It takes into account the quantitative and age composition of the tractor fleet, the technical level of tractors, losses and shortages of products associated with deviations from the agricultural life in the NonBlack Earth Zone of Russia and the costs of repair and maintenance of tractors. The block diagram for this program is shown in Figure 1.
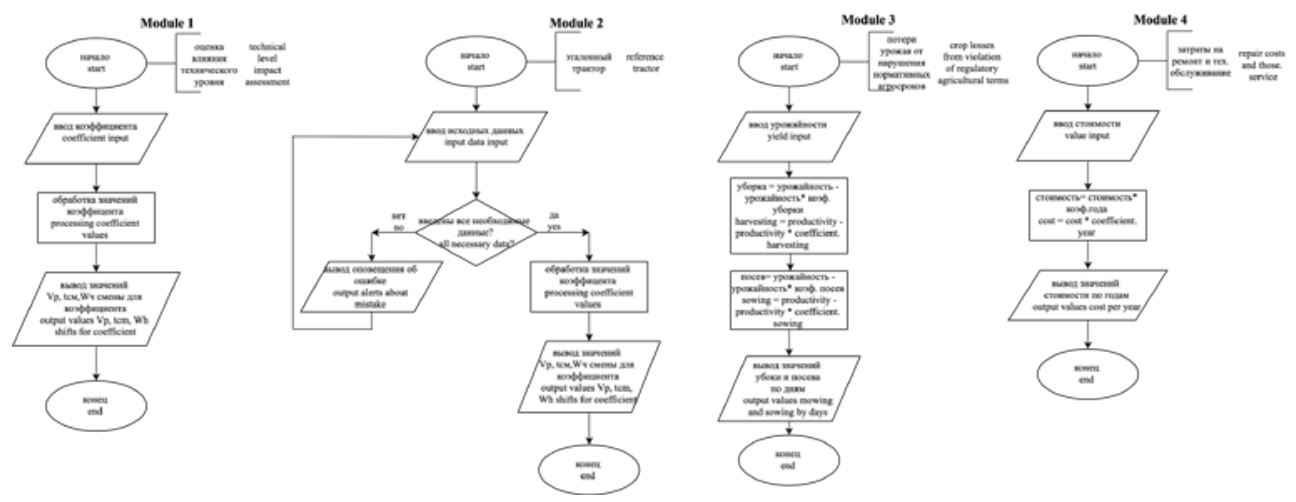

Fig.1. The block diagram for development a software package for the tractor fleet formation in agricultural organizations

The programs make it possible to calculate crop losses from violation of normative agricultural terms in the Central Non-Chernozem Zone for the main crops: potatoes, perennial grasses, winter wheat, barley, corn for silage, beets, and also to estimate the annual cost of repair and maintenance of tractors not only under 10 years of use, but also for the depreciation period, as well as to calculate the quantitative and age point of write-off according to the criterion of minimum total costs for the enterprise in order to save the total costs of the economy. In addition, a set of programs can be used at the design stage, or procurement in order to identify the effectiveness of the design of any tractor. The main recommended requirements of the software package for devices are presented in table 1 .

Table 1. Device system requirements

\begin{tabular}{|l|l|}
\hline Characteristic & Requirement \\
\hline Operating system & Windows $7,8,10$, XP, Vista \\
\hline RAM & 512 megabyte \\
\hline The number of processor cores & 2 \\
\hline CPU frequency & $800 \mathrm{MHz}$ \\
\hline Disk space & 100 megabyte \\
\hline
\end{tabular}

\section{Results and discussions}

The program complex consists of four modules (Fig. 2). The first module allows you to convert physical tractors into reference tractors in order to reduce any unit to agronomic requirements, since the technical need is made in reference tractors (100 hp). Also the module calculates shift coefficient and productivity per hour of shift time automatically for any tractor model. 


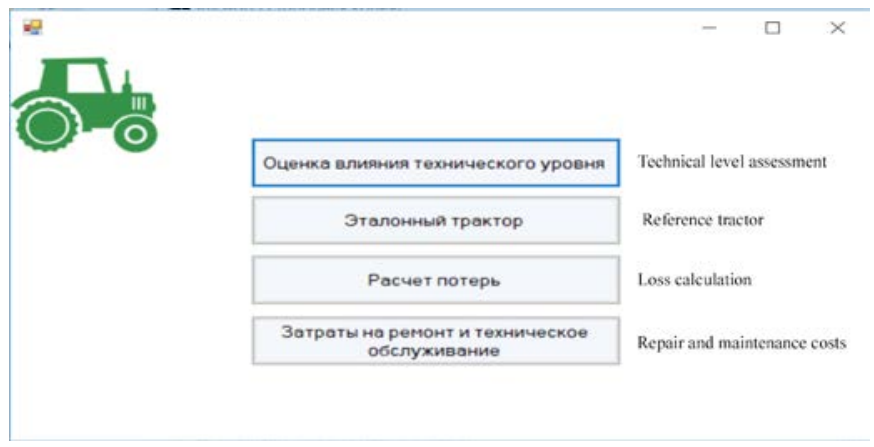

Fig. 2. Program module selection dialog box

The second module is designed to assess the impact of the technical level on productivity per hour of shift time. In addition, the user can calculate the operating speed and the utilization factor of the shift time, which will quickly complete the composition of the tractor fleet even at the procurement stage (Fig. 3). So, for example, the performance of units with hydrodynamic and hydrostatic transmission is generally lower than with a mechanical one due to the lower efficiency of these gears. However, this difference in efficiency is offset by the internal automatism of the hydromechanical and hydrostatic transmission. Tractors of a high technical level, for example, of the Challenger type, have the ability to automate the movement of the unit on the headland. This allows you to increase the performance of the unit by $4 \%$ due to the reduction of losses in idle time. The central position of the control panel allows you to move in arable units when using reversible plows, from the driven way of movement to the shuttle. This, in turn, gives a gain of $4-10 \%$ depending on the length of the headland.

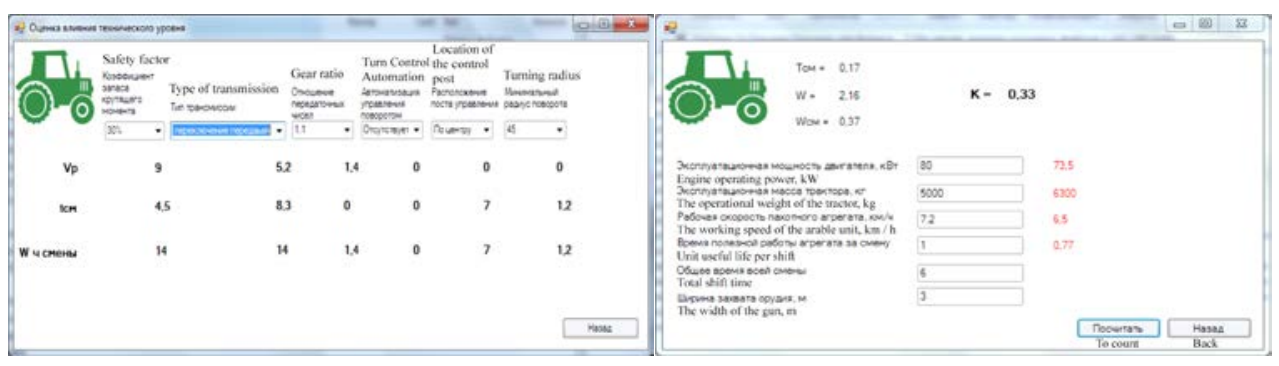

Fig. 3. Examples of calculation of program modules: assessment of technical level impact, conversion of tractors into reference units

The third module of the program calculates product losses when deviating from the agricultural life depending on the actual (maximum allowable yield) for the following crops: potatoes, winter wheat, spring barley, corn for silage, perennial grasses and beets. The user enters into the program the value of the maximum yield that he wants to receive and, depending on this value, the main losses arising from the following mechanized work are calculated: sowing and harvesting. The magnitude of crop losses directly depends on the duration of the agricultural operation. Thus, the user can know in advance the profit that he can get, if you follow agricultural terms. The fourth module estimates the dynamics of the annual cost of repair and maintenance of the tractor, taking into account the age of the tractor. The user fills in the initial data on the cost of tractors in the program, and it automatically displays a graph of the dynamics of costs for repairs and maintenance from 1 to 10 years of use. Thus, the program allows you to predict the cost of repair and maintenance of tractors for the depreciation period. 


\section{Conclusions}

The developed complex of programs allows to complete rationally machine and tractor Park of the agricultural organizations, and also more reasonably to choose the directions of development of a design of a tractor and to be defined with the most effective on cost, productivity and design characteristics models of tractors at the stage of design or purchase. The set of programs can be used in crop enterprises of any size for the following tasks:

1. Planning and forecasting of purchase of tractors at the enterprises;

2. Development of tractor structures at the design stage; hour shift time;

3. Evaluation of the impact of the technical level of the tractor on productivity per

4. Conversion of tractors into reference units for technical needs assessment;

5. Calculation of crop losses from violations of normative agricultural practices in the non-Chernozem zone for the main crops: potatoes, perennial grasses, winter wheat, barley, corn for silage, cabbage, beets;

6. Estimation of annual costs for repair and maintenance of tractors not only in the conditions of 10 years, but also for the amortization period;

7. Calculation of quantitative and age point of write-off of tractors according to the criterion of minimum total costs for the enterprise in order to save the total costs of the economy.

\section{References}

1. A.Yu. Izmailov, V.G. Shevtsov, A.V. Lavrov, Z.A. Godzhaev, V.A. Zubina, Evaluation of the Technical Level of Modern Agricultural Tractors Represented in the Russian Market, SAE Technical Paper № 18SDP-0039 (2018).

2. V.G. Shevtsov, Z.A. Godzhaev, A.V. Lavrov, V.A. Zubina, Methods of determining the optimal composition of the tractor fleet in terms of impaired reproduction of resources, Agricultural machinery and technology. № 4, pp 9-14 (2016).

3. V.A. Zubina, Review and analysis of optimization methods and computer programs to improve the efficiency of the tractor fleet, Bulletin of agrarian science don № 41, pp. 26-32 (2018).

4. V.A. Zubina, Development of software for the formation of the optimal composition of the tractor fleet in conditions of limited resources, Fruit and berry growing in Russia. v. 50, pp 142-147 (2017). 